OPEN

SUBJECT AREAS:

SELF-ASSEMBLY

COORDINATION CHEMISTRY

GELS AND HYDROGELS

SOFT MATERIALS

Received

27 October 2012

Accepted

21 January 2013

Published

7 February 2013

Correspondence and requests for materials should be addressed to A.H. (harada@chem. sci.osaka-u.ac.jp)

\section{Reversible self-assembly of gels through metal-ligand interactions}

\author{
Yuichiro Kobayashi', Yoshinori Takashima', Akihito Hashidzume', Hiroyasu Yamaguchi' \\ \& Akira Harada ${ }^{1,2}$
}

\begin{abstract}
'Department of Macromolecular Science, Graduate School of Science, Osaka University, Toyonaka, Osaka 560-0043, (Japan), ${ }^{2}$ Japan Science and Technology Agency (JST), Core Research for Evolutional Science and Technology (CREST), 7 Gobancho, Chiyoda-ku, Tokyo 102-0076, Japan.
\end{abstract}

Metal-ligand interactions with various proteins form in vivo metal assemblies. In recent years, metallosupramolecular approaches have been utilized to forge an assortment of fascinating two- and three-dimensional nano-architectures, and macroscopic materials, such as metal-ligand coordination polymeric materials, have promise in artificial systems. However to the best of our knowledge, the self-assembly of macroscopic materials through metal-ligand interactions has yet to be reported. Herein we demonstrate a gel assembly formed via metal-ligand interactions using polyacrylamide modified with Fe-porphyrin and L-histidine moieties. The stress values for the assembly increase as the concentration of $\mathrm{Fe}$-porphyrin or L-histidine in the gels increases. Moreover, agitation of Fe-porphyrin gel, Zn-porphyrin gel, and L-histidine gel in an $80 \mathrm{mM}$ Tris-acetate buffer $(\mathrm{pH} 9.0)$ results in selective adhesion of the Fe-porphyrin gel to the L-histidine gel based on the affinities of Fe-porphyrin and Zn-porphyrin with L-histidine.

M etal-ligand interactions play an important role in naturally occurring systems. For example, hemoglobin can bind oxygen efficiently by formation of coordination bond between iron-porphyrin called a heme and L-histidine. Over the past decade, coordination-driven self-assembly has evolved into a well-established methodology for constructing novel metallosupramolecular structures using metal-ligand interactions. A variety of elaborate metallosupramolecules, from two-dimensional polygons to three-dimensional cages, prisms, and polyhedra, have been reported based on coordination-driven self-assembly ${ }^{1-8}$. However to the best of our knowledge, the self-assembly of macroscopic materials through metal-ligand interactions has yet to be reported.

Previously we demonstrated macroscopic assemblies based on molecular recognition, which consisted of polyacrylamide gels modified with hosts and guest moieties ${ }^{9-15}$. Herein we demonstrate a gel assembly formed via metal-ligand interactions using polyacrylamide modified with iron-porphyrin (Fe-Por) and L-histidine (LHis) moieties. Moreover agitation of Fe-Por gel, zinc-porphyrin (Zn-Por) gel, and L-His gel in an $80 \mathrm{mM}$ Trisacetate buffer ( $\mathrm{pH}$ 9.0) results in selective adhesion of the Fe-Por gel to the L-His gel based on the affinities of FePor and Zn-Por with L-His.

\section{Results}

Preparation of gels. Figure 1 shows the 2H-Por $(x)$, Fe-Por $(x)$, and Zn-Por $(x)$ gel ( $x$ denotes the mol $\%$ of the $2 \mathrm{H}$ Por, Fe-Por and Zn-Por moiety) and the L-His $(y)$ gel ( $y$ denote the mol \% of the L-His moiety) that we have designed. The metalloporphyrin gel was prepared by the reaction of metalloporphyrin with an $N$-hydroxy succinimidyl gel, which was prepared by terpolymerization of acrylamide (AAm), $N, N^{\prime}$-methylenebisacrylamide (MBAAm) (cross-linker), and $N$-succinimidyl acrylate (Scheme S1). The L-His gel was prepared by radical terpolymerization of AAm, MBAAm, and the L-His monomer under conventional conditions (Scheme S2). UV-Vis and ${ }^{1} \mathrm{H}$ NMR spectroscopy were used to determine the mol \% of $2 \mathrm{H}-, \mathrm{Fe}-, \mathrm{Zn}-\mathrm{Por}$, and L-His in the gels (Fig. S1-S4).

The gels were cut into $5 \mathrm{~mm} \times 5 \mathrm{~mm} \times 1 \mathrm{~mm}$ pieces. The metalloporphyrin gel was used as prepared due to its easily identifiable color, but the L-His gel was stained red with a dye (food pigment red NO.102). Staining does not affect the association between the metalloporphyrin and the L-His moieties in the gels. Additionally, an acrylamide gel without the metalloporphyrin or L-His moieties was also prepared in a similar manner as a blank gel.

Assembly of the Fe-Por gel with the L-His gel. The Fe-Por gel and the L-His gel immediately adhere to each other upon agitation in an $80 \mathrm{mM}$ Tris-acetate buffer (pH 9.0) (Fig. 2b, Supplementary Movie 1). The assembly formed 


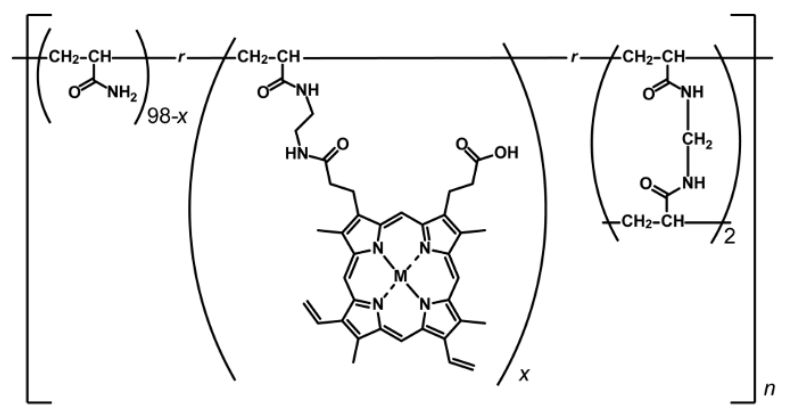

$M=2 \mathrm{H}: 2 \mathrm{H}-\mathrm{Por}(\mathrm{x}) \mathrm{gel}$ Fe : Fe-Por $(x)$ gel $\mathrm{Zn}: \mathrm{Zn}-\mathrm{Por}(\mathbf{x}) \mathrm{gel}$

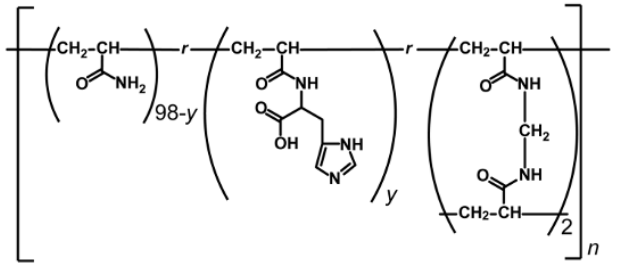

L-His (y) gel

Figure 1 Chemical structures of metalloporphyrin (x) gel and L-His (y) gel. Acrylamide-based gels were modified with metalloporphyrin or L-His moieties, which are denoted as metalloporphyrin (x) gel and L-His (y) gel. $x$ and $y$ indicate the mol \% of metalloporphyrin and L-His moieties, respectively.

from the Fe-Por gel with the L-His gel is strong enough to be picked up using tweezers (Fig. S5). In contrast, agitation of the $2 \mathrm{H}$-Por gel and the L-His gel does not yield an assembly (Fig. S7b), and 2H-Por and L-His do not interact in a homogeneous solution (Fig. S9). Similarly, agitation of pieces of the same type of gel (e.g., Fe-Por gel pieces) or pieces of the blank gel with Fe-Por gel or L-His gel does not lead to assembly formation (Fig. S10, 11). However after metalation of iron to $2 \mathrm{H}$-Por in the gel, the gel adhered to the L-His gel (Scheme S3, Fig. S7d, Supplementary Movie 2). The assembly of the Fe-Por gel with L-His gel showed a $\mathrm{pH}$ dependency. The L-His gel formed an assembly with the Fe-Por gel at $\mathrm{pH} 9.0$, however, no assembly of gels was observed at $\mathrm{pH} 2.0$ (Fig. S12a, 12b). The protonation of nitrogen atoms in the imidazole ring of L-His was suggested to inhibit the binding of L-His to Fe-Por (Fig. S13, S14, S15).

Agitation in a buffer solution containing an $60 \mathrm{mM} \mathrm{L}$-His solution causes the assembly of the Fe-Por gel and L-His gel to dissociate (Fig. 2c, Supplementary Movie 3), then washing with a fresh buffer solution reassembles the gel pieces (Fig. 2d, Supplementary Movie 4). The binding and dissociation of the Fe-Por gel with the L-His gel are reversible.

Macroscopic discrimination by the L-His gel between the Fe-Por gel and the Zn-Por gel. The ability of the L-His gel to form an assembly with the Fe-Por gel and Zn-Por gel was examined by simple agitation. When pieces of the Fe-Por gel, Zn-Por gel, and LHis gel are agitated in an $80 \mathrm{mM}$ Tris-acetate buffer $(\mathrm{pH}$ 9.0), the LHis gel only forms an assembly with the Fe-Por gel but not with the Zn-Por gel (Fig. 3, Supplementary Movie 5). A UV-Vis study on the interactions between metalloporphyrins and L-His in homogeneous solutions has shown that L-His prefers Fe-Por to Zn-Por because the association constant between L-His and Fe-Por is $5.2 \times 10^{3} \mathrm{M}^{-1}$ (Fig. S16, S17), and that of L-His and Zn-Por is $1.4 \times 10^{2} \mathrm{M}^{-1}$ (Fig. S18, S19) ${ }^{16-18}$. These results confirm that the difference of the
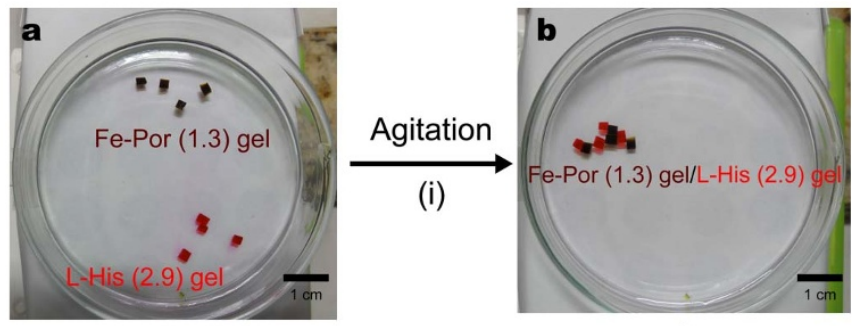

(ii) $\downarrow$ Agitation
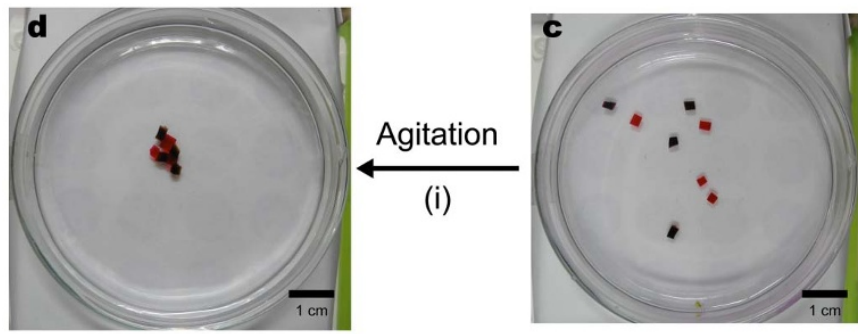

Figure $2 \mid$ Pictures of the assembly, dissociation, and reassembly of Fe-Por (1.3) gel (brown) with L-His (2.9) gel (red). a) Fe-Por (1.3) gel and L-His (2.9) gel were placed in a petri dish, and an $80 \mathrm{mM}$ Tris-acetate buffer ( $\mathrm{pH}$ 9.0) was added. b) Agitation for a few minutes led to a gel assembly. c) The addition of L-His solution and agitation led to the dissociation of the gels. d) These gels were washed using an excess of buffer, and reassembled by agitation in fresh buffer. Solutions (i) $80 \mathrm{mM}$ Tris-acetate buffer ( $\mathrm{pH} 9.0$ ); (ii) L-His solution added to $80 \mathrm{mM}$ Tris-acetate buffer ( $\mathrm{pH} 9.0$ ).

association constant between L-His and Fe-Por or Zn-Por was reflected as the selective adhesion of the L-His gel to the Fe-Por gel.

Adhesion strength of the assembly of the gels. To investigate the adhesion strength of the assembled gels, the rupture stress was measured semi-quantitatively (Table 1). The stress values for an assembly of the Fe-Por (2.7) gel with the L-His gel increase as the concentration of L-His increases from 1.5 to $5.9 \mathrm{~mol} \%$. The $\mathrm{Zn}$-Por (1.6) gel did not form an assembly with L-His (2.9) gel, however, ZnPor gel formed an assembly with L-His gel by increasing the concentration of $\mathrm{Zn}$-Por (1.6) gel and L-His (2.9) gel to 2.7 and $5.9 \mathrm{~mol} \%$ respectively. These results suggested that the mechanical strength of the assembled gels is proportional to the mole content of $\mathrm{Fe}$ - and $\mathrm{Zn}$-Por and L-His in the gels. Different affinities of metals to ligands give specific gel assemblies, demonstrating that metal-ligand interactions play an important role not only on the molecular level, but also on the macroscopic level.

\section{Discussion}

The Fe-Por gel formed an assembly with the L-His gel in an $80 \mathrm{mM}$ Tris-acetate buffer ( $\mathrm{pH} 9.0$ ). In contrast, the $2 \mathrm{H}$-Por gel and the LHis gel does not yield an assembly. However after metalation of Fe (III) to $2 \mathrm{H}$-Por in the gel, the gel forms an assembly with the L-His gel. An assembly of the Fe-Por gel and the L-His gel was separated into each gel by agitation in a solution containing an $60 \mathrm{mM}$ of LHis, and the gels reassembled by washing with a fresh buffer. This result was suggested that the L-His moiety in the gel can recoordinate with Fe-Por instead of with L-His in a solution. These results indicate that metal-ligand interactions are responsible for self-assembly of the gels.

The Fe-Por gel, Zn-Por gel, and L-His gel are agitated, the L-His gel only forms an assembly with the Fe-Por gel. The higher affinity of the L-His for the Fe-Por than that for the Zn-Por led to the selective binding of the Fe-Por gel and L-His gel. 

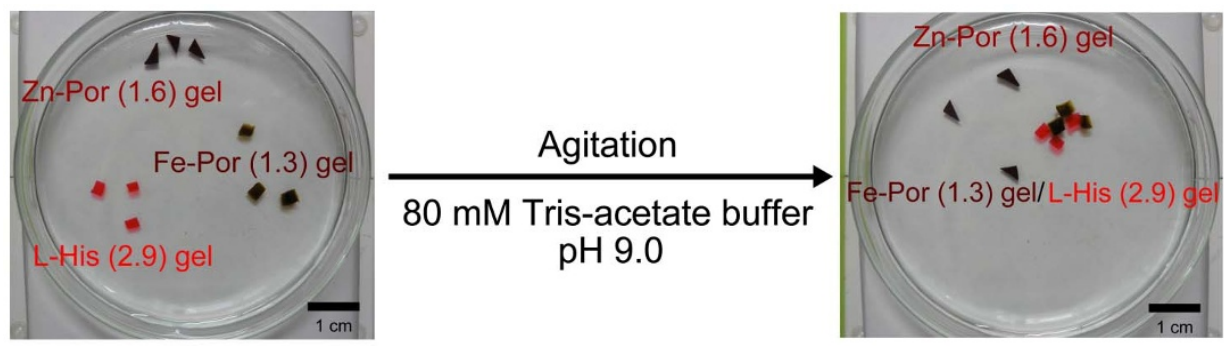

Figure 3 Picture of macroscopic discrimination by L-His (2.9) gel (red) between Fe-Por (1.3) gel (brown) and Zn-Por (1.6) gel (red-brown). Fe-Por (1.3) gel, Zn-Por (1.6) gel (red-brown), and L-His (2.9) gel (red) were placed in a petri dish. The addition of an $80 \mathrm{mM}$ Tris-acetate buffer (pH 9.0) and agitation for a few minutes selectively formed an alternating self-assembly of Fe-Por (1.3) gel and L-His (2.9) gel.

Increasing the concentration of the L-His group in the L-His gel from 1.5 to $5.9 \mathrm{~mol} \%$ increased the stress values for the assembly with Fe-Por gel. And Zn-Por gel formed an assembly with L-His gel by increasing the concentration of Zn-Por (1.6) gel and L-His (2.9) gel to 2.7 and $5.9 \mathrm{~mol} \%$, respectively. These results indicated that the number of metalloporphyrin and L-His group on the surface of the gels was important in the gel assembly. The surface coverage of the metalloporphyrin and L-His groups is expected to govern the adhesion strength of the assembled gel. The adhesion strength of the assembled gel can be regulated by changing the mole content of the metalloporphyrin or L-His group in the gels.

Metal-ligand interactions were utilized for the first time to assemble macroscopic gels. Simple agitation of Fe-Por and L-His gels resulted in selective adhesion. The stress values for an assembly of the metalloporphyrin gel with L-His gel increased as the concentrations of metalloporphyrin and L-His increase, indicating that the mechanical strength at the interface between the metalloporphyrin gel and the L-His gel can be regulated. Various hemes show their catalytic activities when a heme molecule is incorporated into an apoprotein with a Fe-Porphyrin-ligand coordination. We expect that the assembly of Fe-Porphyrin gel with L-His gel through metal-ligand interaction can macroscopically control the catalytic activity. The reversible self-assembly of porphyrin-gel with ligand gel may have a potential as activity controllable catalytic system.

Table 1 | Physical properties of the macroscopic self-assemblies between the metalloporphyrin $(x)$ gel and L-His ( $y$ ) gel

\begin{tabular}{|c|c|c|c|c|}
\hline M-Por & $x(\mathrm{~mol} \%)$ & $y(\mathrm{~mol} \%)$ & Assembly* & Stress $(\mathrm{kPa})^{\dagger}$ \\
\hline \multirow[t]{7}{*}{ Fe-Por } & 0.47 & 2.9 & $\mathrm{~N}$ & - \\
\hline & 1.3 & 1.5 & $\mathrm{~N}$ & - \\
\hline & & 2.9 & $A$ & $1.2 \pm 0.1$ \\
\hline & & 5.9 & $A$ & $1.7 \pm 0.1$ \\
\hline & 2.7 & 1.5 & $A$ & $2.5 \pm 0.3$ \\
\hline & & 2.9 & $A$ & $3.8 \pm 0.2$ \\
\hline & & 5.9 & $A$ & $4.8 \pm 0.4$ \\
\hline \multirow[t]{6}{*}{ Zn-Por } & 1.6 & 1.5 & $\mathrm{~N}$ & - \\
\hline & & 2.9 & $\mathrm{~N}$ & - \\
\hline & & 5.9 & $\mathrm{~N}$ & - \\
\hline & 2.7 & 1.5 & $\mathrm{~N}$ & - \\
\hline & & 2.9 & $\mathrm{~N}$ & - \\
\hline & & 5.9 & $A$ & $1.2 \pm 0.3$ \\
\hline \multirow[t]{2}{*}{ 2H-Por } & 1.4 & 2.9 & $\mathrm{~N}$ & - \\
\hline & 2.9 & 5.9 & $\mathrm{~N}$ & - \\
\hline
\end{tabular}

"Interaction between metalloporphyrin gels and L-His gels; A and N denote assembled and no interactions observed in water or air, respectively. Metalloporphyrin gel and L-His gel interactions were tested at least three times.

TPhysical properties of the gel assemblies obtained by material tension testing machines. Stress was measured three times for each system. Data are averages along with standard deviations. Stress values for assembly of the metalloporphyrin gel with strained and non-stained L-His gel were same.

\section{Methods}

The L-His gel was prepared by a radical terpolymerization of AAm, MBAAm, and the L-His monomer ${ }^{19}$ using conventional conditions (Scheme S1). Immersion into a solution of a red dye (food pigment red NO.102) stained the L-His gel. Then the L-His gel was immersed in excess solvent. The metalloporphyrin gel was prepared by the reaction of $2 \mathrm{H}^{-20}, \mathrm{Fe}^{20}$, or $\mathrm{Zn}-\mathrm{Por}^{21}$ with an $\mathrm{N}$-hydroxy succinimidyl gel, which was prepared by terpolymerization of AAm, MBAAm, and N-succinimidyl acrylate (Scheme S2). Due to its color, the metalloporphyrin gel was used without staining. The mol \% of metalloporphyrin, $x$, was determined by the Lambert-Beer law using the absorbance of a $30 \mu \mathrm{m}$ thick metalloporphyrin gel. The UV-Vis spectra were obtained by a JASCO V-650 spectrophotometer (Fig. S1-S3). The mol \% of L-His, $y$, was determined by a comparison of the integral values of protons in the main chain to that of the imidazole in L-His moiety in ${ }^{1} \mathrm{H}$ NMR spectra (Fig. S4). The gels were cut into millimeter- to centimeter-sized pieces using a knife. Each gel was placed in a petri dish, and $25 \mathrm{~mL}$ of an $80 \mathrm{mM}$ Tris-acetate buffer ( $\mathrm{pH} 9.0$ ) was subsequently added. Then the mixture was agitated at $1000 \mathrm{rpm}$ using Eyela cute mixer CM-1000 at room temperature. The stress-strain curves for the gel assemblies were recorded using a Yamaden RE-33005 Rheoner creep meter in the same manner as our previous report ${ }^{9-15}$. Each sample $\left(5 \times 10 \times 2 \mathrm{~mm}^{3}\right)$ was measured at a rate of $0.1 \mathrm{~mm} \mathrm{~s}^{-1}$ at room temperature. Iron metalation of $2 \mathrm{H}$-Por gel was carried out by adding $2 \mathrm{H}$-Por gel, $\mathrm{FeCl}_{3}$, and sodium acetate were added to glacial acetic acid, which suspension was refluxed (Scheme S3).

1. Rojo, J., Romero-Salguero, F., Uppadine, L. H. \& Lehn, J.-M. Grid type metal ion architectures: functional metallosupramolecular arrays. Angew. Chem. Int. Ed. 43, 3644-3662 (2004).

2. Fujita, M., Tominaga, M., Hori, A. \& Therrien, B. Coordination assemblies from a Pd(II) cornered square complex. Acc. Chem. Res. 38, 369-378 (2005).

3. Fiedler, D., Leung, D. H., Bergman, R. G. \& Raymond, K. N. Selective molecular recognition, $\mathrm{C}-\mathrm{H}$ bond activation, and catalysis in nanoscale reaction vessels. Acc. Chem. Res. 38, 349-358 (2005).

4. Pitt, M. A. \& Johnson, D. W. Main group supramolecular chemistry. Chem. Soc. Rev. 36, 1441-1453 (2007).

5. Zheng, Y.-R. et al. A facile approach toward multicomponent supramolecular structures: selective self-assembly via charge separation. J. Am. Chem. Soc. 132, 16873-16882 (2010).

6. De, S., Mahata, K. \& Schmittel, M. Metal-coordination-driven dynamic heteroleptic architectures. Chem. Soc. Rev. 39, 1555-1575 (2010).

7. Granzhan, A., Schouwey, C., Riis-Johannessen, T., Scopelliti, R. \& Severin, K. Connection of Metallamacrocycles via dynamic covalent chemistry: a versatile method for the synthesis of molecular cages. J. Am. Chem. Soc. 133, 7106-7115 (2011).

8. Argent, S. P. et al. High-nuclearity metal-organic nanospheres: a Cd $\mathrm{C}_{66}$ ball. J. Am. Chem. Soc. 134, 55-58 (2012).

9. Harada, A., Kobayashi, R., Takashima, Y., Hashidzume, A. \& Yamaguchi, H. Macroscopic self-assembly through molecular recognition. Nat. Chem. 3, 34-37 (2011).

10. Yamaguchi, H., Kobayashi, R., Takashima,Y., Hashidzume, A. \& Harada, A. Selfassembly of gels through molecular recognition of cyclodextrins: Shape selectivity for linear and cyclic guest molecules. Macromolecules 44, 2395-2399 (2011).

11. Zheng, Y., Hashidzume, A., Takashima,Y., Yamaguchi, H. \& Harada, A. Macroscopic observations of molecular recognition: Discrimination of the substituted position on the naphthyl group by polyacrylamide gel modified with $\beta$-cyclodextrin. Langmuir 27, 13790-13795 (2011).

12. Hashidzume, A. \& Harada, A. Recognition of polymer side chains by cyclodextrins. Polym. Chem. 2, 2146-2154 (2011).

13. Yamaguchi, H., et al. Photoswitchable gel assembly based on molecular recognition. Nat. Commun. 3, 603 (2012).

14. Zheng, Y., Hashidzume, A., Takashima,Y., Yamaguchi, H. \& Harada, A. Switching of macroscopic molecular recognition selectivity using a mixed solvent system. Nat. Commun. 3, 831 (2012). 
15. Zheng, Y., Hashidzume, A., Takashima, Y., Yamaguchi, H. \& Harada, A. Temperature-sensitive macroscopic assembly based on molecular recognition. ACS Macro Letters, 1, 1083-1085 (2012).

16. Foster, R. Organic Charge-Transfer Complex Academic Press.; New York(1969).

17. Robert, Q., Mario, N. \& Joan, S. V. New five- and six-coordinate imidazole and imidazolate complexes of ferric tetraphenylporphyrin. J. Am. Chem. Soc. 104, 2588-2595 (1982).

18. Kenneth, L. B. A simplified method for spectrophotometric determination of equilibrium constants. Inorganica Chimica Acta 37, L513-L516 (1979).

19. Casolaro, M., Severino, B., Andrea, C., Mendichi, R. \& Ito, Y. L-Proline functionalized polymers prepared by RAFT polymerization and their assemblies as supported organocatalysts. Biomacromolecules 5, 1325-1332 (2004).

20. Matsuo, T., Hayashi, T. \& Hisaeda Y. Supramolecular hemoprotein linear assembly by successive interprotein heme-heme pocket interactions. J. Am. Chem. Soc. 129, 10326-10327 (2007).

21. Onoda, A., Kakikura, Y., Uematsu, T., Kuwabata, S. \& Hayashi ,T. Photocurrent Generation from Hierarchical Zinc-Substituted Hemoprotein Assemblies Immobilized on a Gold Electrode. Angew. Chem. Int. Ed. 51, 2628-2631 (2012).

\section{Acknowledgments}

We gratefully acknowledge the financial support from the Japan Science and Technology Agency (JST), the Core Research for Evolutional Science and Technoloty (CREST) program.

\section{Author contributions}

A. Harada conceived and directed the project. Y.K. and H.Y. designed and performed the experiments. Y.K., H.Y. and A. Harada co-wrote the paper. A. Hashidzume and Y.T. contributed to the result disscussion.

\section{Additional information}

Supplementary information accompanies this paper at http://www.nature.com/ scientificreports

Competing financial interests: The authors declare no competing financial interests.

License: This work is licensed under a Creative Commons

Attribution-NonCommercial-ShareALike 3.0 Unported License. To view a copy of this license, visit http://creativecommons.org/licenses/by-nc-sa/3.0/

How to cite this article: Kobayashi, Y., Takashima, Y., Hashidzume, A., Yamaguchi, H. \& Harada, A. Reversible self-assembly of gels through metal-ligand interactions. Sci. Rep. 3, 1243; DOI:10.1038/srep01243 (2013). 